\title{
Epidemiology and Seasonal Variation of Ixodid Ticks in Dairy Cattle of Gangetic Plains of Uttar Pradesh, India
}

\author{
Karan Veer Singh ${ }^{1}$, Awanish Kumar ${ }^{2}$, Mehar Singh $^{3}$, Kamal Jaiswal $^{2}$, Manishi Mukesh ${ }^{1}$
}

10.18805/ag.D-4983

\begin{abstract}
Background: The Gangetic plain of Uttar Pradesh is fertile land inhabited by second highest cattle population in India. A study was undertaken from May 2016 to March 2018 on the distribution and abundance of ticks in cattle.

Methods: Data was collected from 3 organized farms, 5 Gaushalas and from local farmers. Studied animals were divided into three categories indigenous breeds $(n=450)$, exotic $(n=60)$ and crosses of exotic and local breeds $(n=140)$. The prevalence of tick infestation was studied in the host cattle in the different seasons.

Result: Total eight species of ticks were identified. Among the Ixodid ticks, Rhipicephalus (Boophilus) microplus was the predominant species $(85.28 \%)$ in all seasons. Significantly $(p<0.05)$ higher prevalence was recorded in monsoon season as compared to other seasons. Animals aged 1 year of age (50.87\%). Sex-wise, the males had higher infestation rate than the females. In the villages, Gaushalas and in unorganized dairy farms tick infestation prevalence was (45\%) as compared to minimal prevalence $4 \%$ recorded from organized sector. Infestation in exotic cattle was high in fields as compared to crossbred and indigenous cattle breed. Most of the animals under farm management system were infected with single tick species. While multi species tick infestation was observed in the fields. This could be due to the management practices and timely tick treatment adopted by farms.
\end{abstract}

Key words: Cattle, Ixodid ticks, Rhipicephalus (Boophilus) microplus.

\section{INTRODUCTION}

India is predominantly an agricultural country with $70 \%$ of its population living on income from agriculture. Each rural households own livestock for milk requirement and for additional income. Cattle are multipurpose animals and are raised as dairy animals, as a beef animal, as draught animals and for transportation of goods. The major constraint in the livestock sector is ectoparasite infestation of tick (Colebrook et al. 2004). Tick infestation and diseases caused by them in domestic animals is a common and serious problem.

Ticks are specialized obligate blood-feeding ectoparasite, 713 species of hard ticks have been identified (Barker et al. 2004). Ticks feed on their hosts from few days to weeks, which depends on life stages and host. The cuticle grows to accommodate the large volume of ingested blood. An adult could easily consume 200-600 times their unfed body weight (Sonenshine et al. 1991). Heavy infestation is detrimental to animal health could lead to animal mortality. Ticks also produce endotoxin, which causes sweating sickness in calves. On a global basis, ticks transmit a number of pathogenic organisms like protozoans, rickettsiae, spirochaetes and viruses and also act as vectors and reservoirs for infectious agents (Jongejan and Uilenberg 2004).

Different tick species are widely distributed and are common in all agro-ecological zones of the country (Ghosh et al. 2007). Three members of Genus Rhipicephalus (formerly Boophilus), $R$. Microplus, $R$. annulatus and $R$. australis are considered to be the most important tick parasite of livestock in subtropical and tropical regions. The incidence and prevalence of ticks were reported from
${ }^{1}$ National Bureau of Animal Genetic Resources, Karnal-132 001, Haryana, India.

Babasahib Bhimrao Ambedkar University Lucknow- 226 025, Uttar Pradesh, India.

${ }^{3}$ Animal Husbandry Department, Lucknow-226 025, Uttar Pradesh, India.

Corresponding Author: Karan Veer Singh, National Bureau of Animal Genetic Resources, Karnal-132 001, Haryana, India.

Email: karan.singh2@icar.gov.in

How to cite this article: Singh, K.V., Kumar, A., Singh, M., Jaiswal, K. and Mukesh, M. (2021). Epidemiology and Seasonal Variation of Ixodid Ticks in Dairy Cattle of Gangetic Plains of Uttar Pradesh, India. Agricultural Science Digest. 41(2): 380-384. DOI: 10.18805/ag.D-4983.

Submitted: 02-07-2019 Accepted: 19-10-2020 Online: 02-02-2021

different parts of the country (Kaur et al. 2016, Sanyan et al. 2005). The repeated outbreaks of KFD (Kyasanur forest disease) in Karnataka (Murhekar et al. 2015) and the recent Crimean-Congo hemorrhagic fever (CCHF) in Gujarat has increased public health concern over tick-borne diseases. It necessitates strategic control of tick vectors transmitting diseases to humans. Physical removal with the help of iron clippers or comb and chemical treatments using acaricide is the most suitable and practiced tick controlled methods adopted by farmers. Ticks could be controlled by pasture rotation, environmental modification and integrated biologic and chemical control strategies.

Uttar Pradesh (U.P) state has got the second highest cattle population and highest buffalo population in the country (19 th $^{\text {th }}$ Census). Over 42 different species of ticks has 
Epidemiology and Seasonal Variation of Ixodid Ticks in Dairy Cattle of Gangetic Plains of Uttar Pradesh, India

been reported from the U.P state (Ghosh et al. 2007). However, the Ixodid ticks prevalence studies in the cattle of U.P are very sparse. Ali et al., 2013 and Patel et al., 2012 have studied tick infestation in Azamgarh and Mathura districts of U.P and from Uttarakhand region (former hilly part of the U.P state). The aim of the present study is to assess the tick prevalence in the North Indian Gangetic plains of Uttar Pradesh and to carry out studies to document tick infestation in indigenous cattle breed. Information and periodic data was collected from the villages, Gaushalas and unorganized dairy farms. Government aided two indigenous cattle farm were adopted in Lucknow (U.P state) to record physiological data on tick infestation in different seasons.

\section{MATERIALS AND METHODS Geographical information}

We have surveyed the villages coming under four districts Bareilly, Lucknow, Kanpur and Allahabad of Uttar Pradesh in the fertile Gangetic plains (North India). Periodic data was recorded from two indigenous cattle farms and five Gaushalas maintained under Uttar Pradesh Livestock Development Board (UPLDB) and one private cattle farm. Animals were studied in different seasons and data was recorded monthly. The region's climate corresponds to mild dry winter, hot summer; with dry season extending from MayJuly while Mid July to September is monsoon period with heavy rains and high humidity.

\section{Collection and Identification of ticks}

Adult ticks from cattle were collected from May 2016 to March 2018 , by physically removing with the help of blunt callipers for identification. The specimens were kept in plastic containers with a ventilated cap according to host and the site of attachment. Ticks were identified using standard keys (Sen and Fletcher 1962; Soulsby 2006; Walker et al. 2003).An inventory was conducted with a questionnaire comprising details about the animals and infestation from the field. Animals were randomly selected as sampling unit and were checked thoroughly for any tick infestation. Animals of both sexes and all age groups were examined to record the prevalence of Ixodid ticks infield and from different organized and unorganized dairy farms (Gaushalas). The identified farms/houses were visited monthly to record the information related to infecting species of tick, the number of ticks per infected animal, site of attachment of ticks on the host body, breed of cattle, age, sex of host animal and management practices adopted by the farm.

\section{Clinical records}

Standard physiological data like rectal temperature, respiratory rate, body surface temperature and pulse rate from individual farm animals were collected. Information about animal age, sex, coat color and hair type also recording seasons, temperature and humidity were also recorded.

\section{Statistical analysis}

Statistical analysis was performed on data by SPSS 13.0 software by applying $C h i$ Square test and statistical differences $(P \leq 0.01$ and $P \leq 0.05)$ between various groups were calculated.

\section{RESULTS AND DISCUSSION}

During the study period, four districts of Uttar Pradesh coming under Gangetic Plain area were surveyed for tick infestation. In the villages, farmers prefer to keep milch cattle breed for income generation. The cattle in villages could easily be categorized into three categories. Sahiwal, Gir and Rathi among the indigenous milk breeds while HolsteinFriesian as exotic dairy breed. Different grades of crosses between exotic and cross breed cows were most abundant in fields. Animals in the organized farms were of Sahiwal breed, while in Gaushalas it was a mixed population of local cattle and crosses which are not utilised for milking or are diseased animals. The most common infection sites for adult ticks were the neck, behind ears, underbelly, groin, udder, perennial regions and tail region. Eight tick species were identified from host animals in the region, Hyalomma anatolicum, Hyalomma excavatum, Hyalomma hussaini, Hyalomma brevipunctata, Rhipicephalus(Boophilus) sanguineus, Rhipicephalus (Boophilus) microplus, Rhipicephalus (Boophilus) decoloratus and Haemaphysalis bispinosa. The prevalence of tick infestation on the host cattle was studied in the different seasons. The area witnessed three major seasons summer (March to June), monsoon (July to October) and winter (November to February). The overall prevalence of ticks during the two year study period was $65 \%$. Most of the animal infestation was of single tick species, however, multi-species tick infestation was also recorded from the field. No significant preference for age or sex of the animal was observed. Infestation in exotic cattle was high under field condition as compared to crossbred and indigenous cattle breed, however, due to good management practices and timely treatment in the organized farm the incidence of infestation was very limited. It is a well-known fact that Indian indigenous cattle breed $B$. indicus is resistance to tick infestation. Resistance to ticks is a heritable character (Utech et al., 1978) several workers have estimated the heritability for resistance.

Periodic data from the selected animal farms and Gaushalas were recorded, the animals on the farm were categorized into three, pure indigenous, crossbred and crosses. Each category of animals was further grouped into different age groups for physiological data recording. Information on coat colours (Grouped into, totally white, $>75 \%, 50-75 \%$ and $25-50 \%$ ) and hair type (short straight and long curl) were also collected. Tick infestation was significantly affected by the type of hair on animals. Animals with long and curly hair had a twice number of ticks than animals with short and straight hair as short and curly hair provide hiding grounds and helps them protection against 
bird feeding. After monsoon period the Sept-Oct months it was $(p<0.01)$. During the dry season, tick count was affected by coat color and hair type $(p<0.01)$ (Table 1$)$. However, the animal data from organized farms could not be analyzed based on coat type as all animals were of the same breed.

The tick infestation data month wise and season wise are given in Fig 1 and 2 respectively. In the age-wise tick infestation, maximum positive cases $(72.01 \%)$ were noticed in the age group I (< 1 year) followed by $69.32 \%$ in II group (1-3 years) and minimum in III group (>3 years) (Fig 3). As reported by Manan et al. (2007) age of animals has a role in the infestation pattern of tick species since younger calf are more susceptible to attack. Sutherst et al. (1983) reported that the females of the dairy breed are more susceptible to infestations due to hormonal stress, however, no marked difference was recorded in tick infestation pattern amongst farm animals and sex-effect was not significant in our records. Most farmers of the region are marginalized and have 1 to 2 cattle per family which are kept on natural vegetation as compared to well-established dairy farms with the advanced management system. A significantly higher prevalence of tick infestation was observed in the cattle reared by farmers in the villages $(45 \%)$ as compared to animals reared by the intensive management system. The variations in the prevalence of tick infestation in relation to dairy management practices were found to be significant. Another reason could be structure of animal shelter, earthen floor or untidy sheds aid in tick hiding into the cracks and crevices. During winter cold months ticks hides into cracks and reduces activities, so as to protect themselves, which lead to delayed morphogenesis (Delinger et al. 1985).

During the study period, overall 1500 cattle were examined. In all infestation, $R$. microplus was the predominant tick species in cattle irrespective of the season in the Gangetic plains. $R$. microplus has been reported as the most common cattle tick in Tamil Nadu and Uttar Pradesh

Table 1: Animal record for tick count, season, hair type and coat colour.

\begin{tabular}{|c|c|c|c|c|}
\hline \multirow[t]{2}{*}{ Variable } & \multirow{2}{*}{$\begin{array}{l}\text { No. of } \\
\text { Animals }\end{array}$} & \multicolumn{3}{|c|}{ Number of Ticks } \\
\hline & & Average & $\begin{array}{c}\text { Minimum } \\
\text { (no of anima/s) }\end{array}$ & Maximum \\
\hline 2016 & 466 & 40 & 0 & 422 \\
\hline 2017 & 529 & 44 & 0 & 202 \\
\hline Season Jan - Feb & 222 & 17 & 0 & 116 \\
\hline May - June & 323 & 32 & $0(3)$ & 202 \\
\hline Sept - Oct & 260 & 40 & $0(15)$ & 422 \\
\hline Hair Type Short straight & 370 & 27.7 & 0 & 215 \\
\hline Long-curl & 47 & 53.7 & $0(7)$ & 178 \\
\hline Coat colour Totally white & 35 & 18 & $0(2)$ & 70 \\
\hline$>75 \%$ & 27 & 28 & 0 & 167 \\
\hline $50-75 \%$ & 17 & 47 & $0(17)$ & 280 \\
\hline $25-50 \%$ & $370^{*}$ & 39 & $0(303 *)$ & 242 \\
\hline
\end{tabular}

Note: * Farm animals.

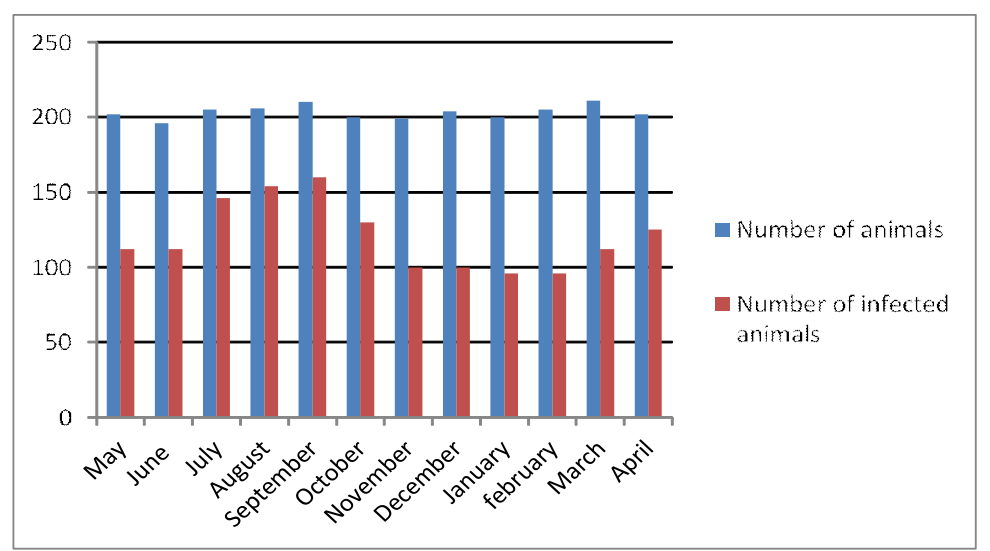

Fig 1: Month wise tick infected animals (year 2016-2017). 
Epidemiology and Seasonal Variation of Ixodid Ticks in Dairy Cattle of Gangetic Plains of Uttar Pradesh, India

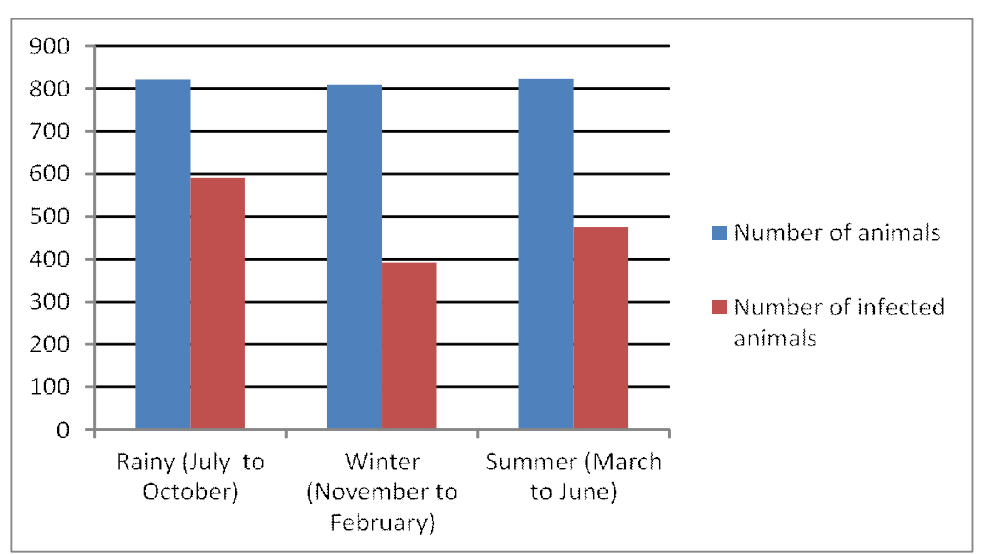

Fig 2: Season wise tick infected animals (year, 2016-17).

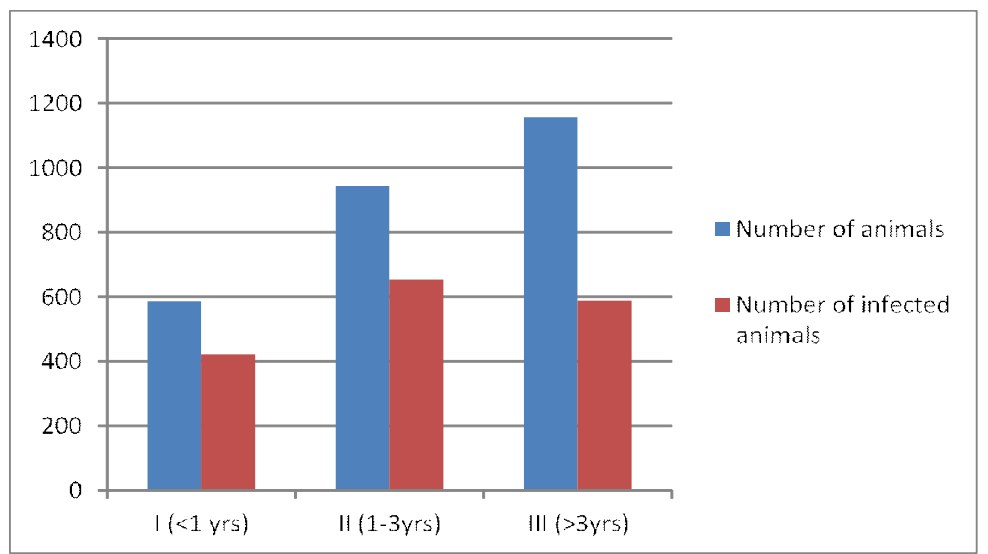

Fig 3: Age wise tick infected animals (year, 2016-17).

(Kumar et al., 2002; Patel et al., 2012). There are many reasons for single tick species dominance on animals. The foremost is the establishment of modern dairy farms with advanced management practices. Second is the farmer's preference for high milk yielding animals, which has resulted in the exponential rise of exotic and crossbred cattle in dairy farming. Tick preference for single host life. A similar dominance of $R$. microplus in organized farms has been earlier reported by Vatsya et al. (2007).

The study showed that the prevalence of ticks in the region has a seasonal pattern of distribution. Variation in tick infestation was recorded in different seasons the maximum infestation was recorded during the rainy period followed by summers and least in the winter months. The variation in the season is due to factors like climatic conditions, parasite-host association and lifestyle of animals. Monsoon period in the sub-tropical country like India is much awaited time for annual rains in the North and proper care should be taken at this time to prevent breeding grounds of ticks. In a study in Mathura district of Uttar Pradesh, the highest prevalence was reported during rainy season $(69.46 \%)$ followed by summer $(62.55 \%)$ and least during winter months (47.96\%). High infestation in monsoon period was reported by other workers (Tadesse et al., 2012). The higher prevalence of ticks in the rainy season suggests that humidity and abundant vegetation growth gives a favourable microclimate for tick larvae to grow (Kumar, 1996). On studying the pattern of distribution of ticks in different agroclimatic zones of Punjab state showed a significant association and high prevalence of $R$. microplus in the zones with high rainfall (Shahardar et al., 1998, Ghai et al. 2008). Rearing practices adopted by the farmer has influencing effect on tick infestation. The majority of the farmer community do semi-intensive animal rearing hence, proper sanitation of the cattle shed is the most important criteria for prevention of tick. Coat color and type of hair shows influencing number of tick counts. More focus should be given on the tick attachment site and distribution pattern on the body surface for a better understanding of prevention and control of ticks. Observations from the present study may contribute to the increased understanding of the epidemiology of ticks in the area.

The Indian native cattle breeds are less susceptible to tick infestation. Tick resistant breeds of cattle have now been developed in an effort to find animals which are adapted to the tropical environment and are also productive for milk under tick challenge. Such animals should be from the elite bulls with high tick resistance and mother with good milk production. In conclusion, we found that tick control can be effectively done by selection of resistant animals. Genetic improvement program should utilize the use of indigenous resistance breed. However, real hurdle in selection is to 
identify and explore the presence of genetic resistance to ticks in a given population.

\section{ACKNOWLEDGEMENT}

The authors thank the cattle owners in Uttar Pradesh region for providing blood samples. We also thank Dr M.P. Singh Gaur, In-charge, Niblet farm, Lucknow for helping data collection, Mr. Naresh Yadav, technical officer, ICAR-NBAGR for assisting in collection. The facilities and support provided by the BBAU, Lucknow is greatly acknowledged.

\section{REFERENCES}

$19^{\text {th }}$ Livestock Census (2012). All India report. http://dehd.nic.in/ sites/default/files/livestock\%20\%205.pdf. 2.2.2016.

Ali, S.Z. and Singh, R.P. (2013). Observation on the prevalence of habitat of full-fed Ixodid ticks in Azamgarh district of Eastern Uttar Pradesh. Indian Journal of Science and Research. 4(2): 193-194.

Barker, S.C. and Murrell, A. (2004). Systematic and evolution of ticks with a list of valid genus and species names. Parasitology. 129: S15-S36.

Colebrook, E. and Wall, R. (2004). Ectoparasites of livestock in Europe and the Mediterranean region. Veterinary Parasitology. 120: 251-274.

Delinger, D. (1985). Hormonal control of diapause. In: Comprehensive insect physiology biochemistry and pharmacology, [Kerkutt G.A., Gilbert L.I. (eds.)] vol 8. Pergamon Press, New York, pp 335-412.

Ghai, J.K., Singh, M. and Singh, A. (2008). Population dynamics of Ixodid ticks infesting cattle in Bathinda and Hoshiarpur districts in the Punjab State. Annals of Biology. 24: 95100.

Ghosh, S., Bansal, G.C., Gupta, S.C., Ray, D., Khan, M.Q., Irshad, H. (2007). Status of tick distribution in Bangladesh, India and Pakistan. Parasitology Research. 101(2): S207S216.

Jongejan, F. and Uilenberg, G. (2004). The global importance of ticks. Parasitology. 129: S3-S14.

Kaur, H., Chhilar, J.S. and Chhillar, S. (2016). Mitochondrial 16s rDNA based analysis of some hard ticks belonging to genus Hyalomma Koch, 1844 (Acari:Ixodidae). The Journal of Advances in Parasitology. 3(2): 32-48.

Kumar, K. and Balakrishanan, N. (2002). Prevalence of ixodid ticks in Nilgiri district of Tamil Nadu state (India). Journal of Communicable Diseases. 34: 124-127.

Kumar, R. (1996). Studies on tick infestations in cattle and buffaloes. M.V.Sc. Thesis submitted to C.S.A., University of Agriculture and Technology, Kanpur, pp 1-178.

Manan, A., Khan, Z., Ahmad, B. and Abdullah (2007). Prevalence and identification of Ixodid tick genera in frontier region Peshawar. Journal of Agriculture and Biological Science. 2: 21-25.
Murhekar, M.V., Kasabi, G.S., Mehendale, S.M., Mourya, D.T., Yadav, P.D., Tandale, B.V. (2015). On the transmission pattern of Kyasanur Forest disease (KFD) in India. Infectious Diseases of Poverty. 4: 37. doi:10.1186/s40249-0150066-9.

Patel, G., Daya-Shanker, Jaiswal, A.K., Sudan, V., Kumar, S. and Verma, J. (2012). Prevalence and seasonal variation in ixodid ticks on cattle of Mathura district, Uttar Pradesh. Journal of Parasitic Diseases. 37(2): 173-176.

Sanyan, A.K., De, S.K. (2005). Status of ticks (Acari: metastigmata) of Rajasthan Records of Zoological Survey of India. 104. (3-4): 129-136.

Sen, S.K. and Fletcher, T.B. (1962). Veterinary Entomology and Acarology for India. Indian Council of Agriculture Research, New Delhi, edition I, 668 pp.

Shahardar, R.A., Niphadkar, S.M., Narsapur, V.S. and Gatne, M.L., (1998). Ixodid ticks of cattle and buffaloes in coastal districts of Maharashtra state. Indian Veterinary Journal 75: 503-06.

Sonenshine, D.E. (1991). Biology of ticks, Oxford University Press, New York. 1: 345.

Soulsby, E.J.L. (2006). Helminths, arthropods and protozoa of domesticated animals. 7. London: Bailliere Tindall and Cassel Ltd. pp. 444-475.

SPSS 13.0 software.

Sutherst, R.W., Kerr, J.D. and Maywald, G.F. (1983). Effect of season and nutrition on the resistance of cattle to the tick Boophilusmicroplus. Australian Journal of Agricultural Research. 34: 329-39.

The Tropical Medical Bureau, http://www.tmb.ie/destination/ news . asp?title $=42$-under-surveillance-over-CrimeanCongo-Fever-case-in-Indian-State-of-Gujaratandid= 182195.

Utech, K.B.W., Wharton, R.H., Kerr, J.D., (1978). Resistance to Boophilus microplus (Canestrini) in different breeds of cattle. Australian Journal of Agricultural Research. 29: 885-895.

Vatsya, S., Yadav, C.L., Kumar, R.R. and Garg, R. (2007). Seasonal activity of Boophilus microplus on large ruminants at an organized livestock farm. Journal of Veterinary Parasitology. 21: 125-28.

Tadesse, F., Abadfaji, G., Girma, S., Kumsa, B. and Tariku, J. (2012). Identification of tick species and their preferred site on cattle's body in and around MizanTeferi, Southwestern Ethiopia. Journal of Veterinary Medicine and Animal Health. 4(1): $1-5$.

Walker, A.R., Bouattour, A., Camicas, J.L., Estrada Pena, A., Horak, I.G., Latif, A.A., Pegram, R.G., Preston, P.M. (2003). Ticks of domestic animals in Africa: a guide to the identification of species. Biosci Rep. pp 1-221. 